Nevșehir Bilim ve Teknoloji Dergisi TARGíd Özel Sayı 199-207 2016

DOI: 10.17100/nevbiltek.210989

URL: http://dx.doi.org/10.17100/nevbiltek.210989

\title{
Yüzey Sulama Yönteminden Damla Sulama Yöntemine Geçişin Starkrimson Delicious EIma Çeşidinin Muhafazası Üzerine Etkileri
}

\author{
Cemile Ebru Onursal* , Cenk Küçükyumuk, Özgür Çalhan, İsa Eren \\ Atakan GÜNEYLİ, Tuba SEÇMEN \\ Meyvecilik Araştırma Enstitüsü Müdürlüğü, Eğirdir, Isparta
}

$\ddot{O} \mathbf{z}$

Çalışmada, çöğür anaç üzerine aşılı 20 yaşındaki Starkrimson Delicious elma çeşidi kullanılmıştır. Damla sulama uygulamalarında iki farklı sulama aralığı ( $\mathrm{I}_{1}=4$ gün ve $\mathrm{I}_{2}=7$ gün) ve 4 farklı pan katsayısı (A sınıfı buharlaşma kabından olan buharlaşma miktarı $\mathrm{Kp}_{1}=0.50, \mathrm{Kp}_{2}=0.75, \mathrm{Kp}_{3}=1.0, \mathrm{Kp}_{4}=1.25$ ) ve salma sulama uygulaması olmak üzere toplam 9 uygulama yapılmıştır. Optimum zamanda derilen meyveler $0^{\circ} \mathrm{C}$ sıcaklık ve $\% 90 \pm 5$ oransal nem koşullarında 6 ay süreyle depolanmıştır. Depolama periyodu süresince aylık aralıklarla alınan meyve örneklerinde ağırlık kaybı, meyve kabuk rengi, meyve eti sertliği, suda çözünür toplam kuru madde (SÇKM), titre edilebilir asit (TEA) miktarı belirlenmiştir. Çalışma sonucunda muhafaza süresince ortalama en az ağırlık kayb1 $\mathrm{I}_{1} \mathrm{Kp}_{2}$ uygulamasından (\%3.40) elde edilirken, en fazla ağırlık kayıpları ise $\mathrm{I}_{1} \mathrm{Kp}_{1}$ (\%4.22), $\mathrm{I}_{1} \mathrm{Kp}_{4}$ (\%3.97) ve salma sulama (\%3.96) uygulamalarında meydana gelmiştir. $\mathrm{I}_{1} \mathrm{Kp}_{1}$ ve $\mathrm{I}_{2} \mathrm{Kp}_{1}$ uygulamaları en yüksek meyve eti sertliği değerlerinin (14.46-14.39 lb) gözlendiği uygulamalar olmuştur. Muhafaza periyodu süresince TEA kaybının önlenmesinde $\mathrm{I}_{1} \mathrm{Kp}_{1}(0.37 \mathrm{~g} / 100 \mathrm{ml})$ ve $\mathrm{I}_{1} \mathrm{Kp}_{2}(0.35$ $\mathrm{g} / 100 \mathrm{ml}$ ) uygulamaları, diğer uygulamalara göre daha etkili bulunmuştur.

Anahtar Kelimeler: Starkrimson Delicious, elma, damla sulama, depolama, kalite

\section{Effects of Transition From Flood Irrigation to Drip Irrigation Method on Storage of Starkimson Delicious Apple Variety}

\begin{abstract}
Research material was 20 years old, drafted on seedling rootstock, apple trees of Starkimson Delicious cultivar in this study. Total number of 9 treatments consisted of; drip irrigation treatments within two different irrigation intervals ( $\mathrm{I}_{1}=4$ days, $\mathrm{I}_{2}=7$ days) and four different pan coefficients (the amount of evaporated water from class $\mathrm{A}$ pan $\mathrm{Kp}_{1}=0.50, \mathrm{Kp}_{2}=0.75, \mathrm{Kp}_{3}=1.0, \mathrm{Kp}_{4}=1.25$ ) and traditional flood irrigation method were used. Fruits which were harvested on optimum harvest time, stored at $0^{\circ} \mathrm{C}$ temperature and $90 \pm 5 \%$ relative humidity for six months. During the storage period, monthly taken fruit samples were analyzed for fruit quality parameters, which are: weight loss, fruit peel colour, firmness, total soluble solid and titratable acidity.

The lowest weight loss (3.40\%) was obtained from $\mathrm{I}_{1} \mathrm{Kp}_{2}$ treatment while the highest values were found in $\mathrm{I}_{1} \mathrm{Kp}_{1}(4.22 \%), \mathrm{I}_{1} \mathrm{Kp}_{4}$ (3.97\%) and flood irrigation (3.96\%) treatments. $\mathrm{I}_{1} \mathrm{Kp}_{1}$ and $\mathrm{I}_{2} \mathrm{Kp}_{1}$ treatments displayed the highest flesh firmness values ((14.46$14.39 \mathrm{lb}) . \mathrm{I}_{1} \mathrm{Kp}_{1}(0.37 \mathrm{~g} / 100 \mathrm{ml})$ and $\mathrm{I}_{1} \mathrm{Kp}_{2}(0.35 \mathrm{~g} / 100 \mathrm{ml})$ treatments were found more effective in preventing the loss of titratable acidity than other treatments during the storage period.
\end{abstract}

Keywords: Starkrimson Delicious, apple, drip irrigation, storage, quality

\footnotetext{
*e-mail: ebru.onursal@gmail.com
} 
1. Giriş

Türkiye'de, 2014 yılı verilerine göre 2.480.444 ton elma üretilmektedir [1]. Isparta ilinde ise elma 610.838 ton ile en fazla üretilen meyve türü olup, Türkiye elma üretiminin yaklaşık \%22'sini tek başına karşılamaktadır [2]. Bölgede en çok üretilen elma çeşidi Red Delicious elma grubudur. Bölge ekonomisi açısından çok önemli bir yere sahip olan elma üretimindeki en önemli sıkıntılardan biri sulamadır. Sulama, meyve verim ve kalitesini etkileyen, diğer uygulamaların etkinliğini arttıran önemli bir girdidir [3]. Sulama ile verim, kalite ve hasat sonrası dayanma gücü karşılıklı etkileşim gösterirler [4]. Eğirdir yöresi elma üreticilerinin durum ve sorunlarının belirlenmesine yönelik yapılan bir çalışmada araştırıcılar, üreticilerin \% 96'sının sulamayı tamamen kendi gözlemlerine dayanarak yaptıklarını belirtmişlerdir [5]. Bu sonuç, sulama suyunun üreticiler tarafından kontrolsüz, herhangi bir bilgi birikimine dayanmadan, bilinçsizce kullanıldığını göstermektedir.

Son yıllarda görülen yağış rejiminin düzensizliği ve kurak periyodların uzunluğu, bitkisel yetiştiricilikte sulamanın önemini daha da arttırmıştır. Sulamadan beklenen yararın sağlanabilmesi; iklim, toprak ve bitki koşullarına uygun sulama yönteminin seçilmesi, seçilen yönteme ilişkin sistemin iyi planlanması, sulama aralığının ve her sulamada uygulanacak sulama suyu miktarının doğrulukla belirlenmesine bağlıdır [3]. Hem dünyada hem de Türkiye'de, özellikle son otuz yıl içerisinde, modern sulama teknolojilerinin kullanımı hızla yaygınlaşmıştır [6]. Sulama yöntemleri içerisinde, üniform su kullanımı, yüksek randıman, sulama suyu tasarrufu ve işletme kolaylığı bakımından, özellikle topraktaki nem eksikliğine duyarlı ve ekonomik verimi yüksek olan bitkiler ile meyve ağaçlarının sulanmasında damla sulama yöntemi ön plana çıkmaktadır [7].

Meyve üreticileri tarafindan damla sulama yönteminin giderek daha fazla kabul görmesi sonucu bu yöntemin kullanıldığı arazi miktarında gün geçtikçe artış olmakta, bu durum Eğirdir yöresinde de benzer şekilde görülmektedir. Ancak son yıllarda bu geçişin artmasıyla birlikte Eğirdir yöresinde üreticilerle yapılan görüşmelerde üreticilerin damla sulama yöntemiyle ilgili birtakım endişelere sahip oldukları görülmüştür [8]. Bazı üreticilerin yüzey sulama yöntemlerine göre daha az su kullanılan damla sulama yöntemine geçtiklerinde, su miktarı azalmasından dolayı meyve kalitesinin bozulması dolayısıyla ürünün depolama kalitesi ve ömrünün azalması gibi endişeler taşımaları nedeniyle, damla sulama yöntemine geçiş yapmakta kararsız oldukları, halen yüzey sulama yöntemlerini uyguladıkları, geçiş yapanların ise herhangi bir temel bilgiye dayanmadan tamamen kendi ve çevredekilerin gözlem ve bilgisine dayalı olarak bilinçsizce sulama yaptıkları görülmüş̧ür.

Bu çalışmanın amacı; verim çağında uzun yıllardır yüzey sulama yöntemleri (salma sulama) ile sulanan elma bahçelerinde damla sulama yöntemine geçişin, meyvelerin depolama kalitelerinin üzerine etkisinin ortaya konulmasıdır.

\section{Materyal ve Metot}

Araştırma; 2009 yılında Meyvecilik Araştırma Enstitüsü Müdürlüğü'ne (Eğirdir/Isparta) ait deneme parselinde yürütülmüştür. Araştırma materyali olarak; 20 yaşında, çöğür anaç üzerine aş11 $5 \times 4 \mathrm{~m}$ sıra arası ve sıra üzeri dikim mesafesinde yetiştirilen Starkrimson Delicious elma çeşidinden alınan meyve örnekleri kullanılmıştır. 
Denemede damla ve salma sulama olmak üzere iki farklı sulama yönteminin meyvelerin muhafaza süresi ve kalitesine olan etkileri incelenmiştir. Bu amaçla bahçenin bir kısmında geçmişten beri yapılan salma sulama uygulamasına devam edilirken, geri kalan kısmında farklı damla sulama programları uygulanmıştır. Denemede ağaçlara damla sulama uygulamalarında 4 ve 7 gün sulama aralıklarında ( $\mathrm{I}_{1}=4$ gün, $\mathrm{I}_{2}=7$ gün) A sınıfı buharlaşma kabından olan buharlaşma toplamının $\% 50, \% 75$, $\% 100$ ve $\% 125$ 'i $\left(\mathrm{Kp}_{1}=0.50, \mathrm{Kp}_{2}=0.75, \mathrm{Kp}_{3}=1.00, \mathrm{Kp}_{4}=1.25\right)$ kadar sulama suyu ve salma sulama uygulamaları olmak üzere toplam 9 uygulama yapılmıştır. Damla sulama uygulamalarında çiçeklenme periyodu sonunda 0-120 cm toprak derinliğindeki mevcut nem tarla kapasitesine getirilmiş, bu tarihten itibaren programlı sulamalara başlanmıştır. Salma sulama uygulamasında ise yörede üreticilerin genel olarak sulamaya başladığı tarih (20 Haziran) ve geleneksel olarak uyguladıkları sulama aralığı dikkate alınarak 20 gün sulama aralığında sulama yapılmış, her sulamada 0-120 $\mathrm{cm}$ toprak derinliğindeki mevcut nem tarla kapasitesine getirilene kadar sulama suyu uygulaması yapılmıştır. Uygulamalar aşağıdaki şekilde gruplandırılmıştır;

4 gün sulama aralı̆̆ (II=4 gün) uygulamalarl:

$\mathrm{S}_{1}\left(\mathrm{I}_{1} \mathrm{Kp}_{1}\right)$ : A sınıfı buharlaşma kabından olan buharlaşma toplamının \%50'si kadar sulama suyu uygulaması

$\mathrm{S}_{2}\left(\mathrm{I}_{1} \mathrm{Kp}_{2}\right)$ : A sınıfi buharlaşma kabından olan buharlaşma toplamının \%75'i kadar sulama suyu uygulaması

$\mathrm{S}_{3}\left(\mathrm{I}_{1} \mathrm{Kp}_{3}\right)$ : A sınıfı buharlaşma kabından olan buharlaşma toplamının \%100’ü kadar sulama suyu uygulaması

$\mathrm{S}_{4}\left(\mathrm{I}_{1} \mathrm{Kp}_{4}\right)$ : A sınıfı buharlaşma kabından olan buharlaşma toplamının \%125'i kadar sulama suyu uygulaması

7 gün sulama aralı̆̆l (I2=7 gün) uygulamalarl:

$\mathrm{S}_{5}\left(\mathrm{I}_{2} \mathrm{Kp}_{1}\right)$ : A sınıfi buharlaşma kabından olan buharlaşma toplamının \%50'si kadar sulama suyu uygulaması

$\mathrm{S}_{6}\left(\mathrm{I}_{2} \mathrm{Kp}_{2}\right)$ : A sınıfi buharlaşma kabından olan buharlaşma toplamının \%75'i kadar sulama suyu uygulaması

$\mathrm{S}_{7}\left(\mathrm{I}_{2} \mathrm{Kp}_{3}\right)$ : A sınıfı buharlaşma kabından olan buharlaşma toplamının \%100’ü kadar sulama suyu uygulaması

$\mathrm{S}_{8}\left(\mathrm{I}_{2} \mathrm{Kp}_{4}\right)$ : A sınıfi buharlaşma kabından olan buharlaşma toplamının \%125'i kadar sulama suyu uygulaması

$\mathrm{S}_{9}: 20$ gün sulama aralığında her sulamada $0-120 \mathrm{~cm}$ toprak derinliğindeki mevcut nemi tarla kapasitesine getirecek kadar sulama suyu uygulamas1

Uygulamalardan sonra nişasta skalası kullanılarak [9] optimum zamanda derilen meyveler $0^{\circ} \mathrm{C}$ sıcaklık ve $\% 90 \pm 5$ oransal nem koşullarında 6 ay süreyle depolanmıştır. Depolama periyodu süresince aylık aralıklarla alınan meyve örneklerinde ağırlık kaybı, meyve kabuğu rengi, meyve eti sertliği, SÇKM ve TEA miktarı tespit edilmiştir. Deneme tesadüf parselleri deneme desenine göre 3 tekerrürlü ve her tekerrürde 10 meyve olacak şekilde kurulmuştur. Denemeden elde edilen veriler JMP 7 istatistik paket programı kullanılarak varyans analizine tabi tutulmuş, depolama dönemleri ortalamaları ile uygulamalar ortalamaları arasındaki farklılıklar LSD çoklu karşılaştırma testine $(\mathrm{P}<0.05)$ göre gruplandırılmış̧ır.

\section{Bulgular ve Tartışma}

2009 yılında deneme parselindeki ağaçlara uygulanan sulama suyu miktarları (Ir), bitki su tüketimi (Et), buharlaşma ve yağış miktarı Tablo 1'de verilmiştir. Damla sulama uygulamalarında sulama suyu miktarı 313.6-705.8 mm arasında değişmiştir. Yüzey sulama uygulamasında ise $917.3 \mathrm{~mm}$ su uygulanmıştır. Bitki su tüketimi damla sulama uygulamalarında 437.2-849.9 mm arasında değişirken yüzey sulama uygulamasında $969.3 \mathrm{~mm}$ olarak belirlenmiştir. 


\begin{tabular}{|c|c|c|}
\hline Uygulama & Sulama suyu miktarı $\left(\mathrm{I}_{\mathrm{r}}\right)(\mathrm{mm})$ & Bitki su tüketimi $\left(\mathrm{E}_{\mathrm{t}}\right)(\mathrm{mm})$ \\
\hline $\mathrm{I}_{1} \mathrm{Kp}_{1}$ & 315.1 & 437.2 \\
\hline $\mathrm{I}_{1} \mathrm{Kp}_{2}$ & 445.3 & 564.2 \\
\hline $\mathrm{I}_{1} \mathrm{Kp}_{3}$ & 575.5 & 666.5 \\
\hline $\mathrm{I}_{1} \mathrm{Kp}_{4}$ & 705.8 & 799.6 \\
\hline $\mathrm{I}_{2} \mathrm{Kp}_{1}$ & 313.6 & 495.7 \\
\hline $\mathrm{I}_{2} \mathrm{Kp}_{2}$ & 443.0 & 608.8 \\
\hline $\mathrm{I}_{2} \mathrm{Kp}_{3}$ & 572.5 & 723.4 \\
\hline $\mathrm{I}_{2} \mathrm{Kp}_{4}$ & 702.2 & 849.9 \\
\hline Yüzey sulama & 917.3 & 969.3 \\
\hline Buharlaşma & \multicolumn{2}{|c|}{874.8} \\
\hline Yağış miktarı & \multicolumn{2}{|c|}{70.4} \\
\hline
\end{tabular}

Starkrimson Delicious elma çeşidinde ağırlık kaybı muhafazanın 30., 120. ve 180. gününde ortalama sırasıly \%1.37, \%4.09 ve \%6.08 olarak saptanmıştır (Tablo 2). Denemede ağırlık kaybı bakımından uygulamalar arasındaki fark istatistiksel olarak önemli $(\mathrm{p}<0.05)$ bulunmuştur. Uygulamalar arasında muhafaza süresince ortalama en az ağırlık kaybı, 4 gün sulama aralığında A sınıfı buharlaşma kabından olan buharlaşma toplamının \%75'i kadar (\%3.40) ve 7 gün sulama aralığında A sınıfı buharlaşma kabından olan buharlaşma toplamının \%100'ü kadar (\%3.41) sulama suyu uygulananlarda olmuştur. En fazla ağırlık kaybının görüldüğü uygulamalar ise 4 gün sulama aralığında A sınıfı buharlaşma kabından olan buharlaşma toplamının \%50'si (\%4.22) ve \%125’i (\%3.97) kadar sulama suyu uygulamaları ile 20 gün sulama aralığında mevcut nemi tarla kapasitesine getirecek (\%3.96) sulama suyu uygulamalarıdır. Kısıtlı sulama ve optimum sulama uygulamalarından elde edilen meyvelerdeki kutikula, aşırı sulama yapılan meyvelerdeki kutikulaya göre sürekli ve daha kalındır. Aşırı sulama uygulamalarından elde edilen meyvelerdeki su kaybının kısıtlı ve optimum sulama uygulamalarından elde edilen meyvelere göre daha fazla olması exodermis yapısındaki bu farklılıkla açıklanabilir [10].

Tablo 2. Starkrimson Delicious elma cesidinde muhafaza süresince saptanan ağırlık kayıpları (\%)

\begin{tabular}{lccccccc}
\multicolumn{7}{c}{ Tablo 2. Starkrimson Delicious elma çeşidinde muhafaza süresince saptanan ağırlık kayıları (\%) } \\
\cline { 2 - 8 } Uygulama & \multicolumn{7}{c}{ Muhafaza Süresi (Ay) } \\
\cline { 2 - 8 } & 1.67 & 2.72 & 3.91 & 4.62 & 5.63 & 6.80 & $\begin{array}{c}\text { Uygulama } \\
\text { Ortalamaları }\end{array}$ \\
\hline $\mathrm{S}_{1}\left(\mathrm{I}_{1} \mathrm{Kp}_{1}\right)$ & 1.25 & 2.09 & 3.10 & 3.73 & 4.69 & 5.55 & $3.22 \mathrm{a}^{\mathrm{z}}$ \\
$\mathrm{S}_{2}\left(\mathrm{I}_{1} \mathrm{Kp}_{2}\right)$ & 1.30 & 2.22 & 3.26 & 4.01 & 4.84 & 5.74 & $3.56 \mathrm{cde}$ \\
$\mathrm{S}_{3}\left(\mathrm{I}_{1} \mathrm{Kp}_{3}\right)$ & 1.46 & 2.51 & 3.68 & 4.38 & 5.33 & 6.44 & $3.97 \mathrm{~b}$ \\
$\mathrm{~S}_{4}\left(\mathrm{I}_{1} \mathrm{Kp}_{4}\right)$ & 1.30 & 2.27 & 3.43 & 4.09 & 5.04 & 6.14 & $3.71 \mathrm{c}$ \\
$\mathrm{S}_{5}\left(\mathrm{I}_{2} \mathrm{Kp}_{1}\right)$ & 1.43 & 2.30 & 3.39 & 3.98 & 4.93 & 5.91 & $3.66 \mathrm{~cd}$ \\
$\mathrm{~S}_{6}\left(\mathrm{I}_{2} \mathrm{Kp}_{2}\right)$ & 1.30 & 2.07 & 3.30 & 3.71 & 4.39 & 5.70 & $3.41 \mathrm{e}$ \\
$\mathrm{S}_{7}\left(\mathrm{I}_{2} \mathrm{Kp}_{3}\right)$ & 1.22 & 2.10 & 3.20 & 3.83 & 4.75 & 5.90 & $3.50 \mathrm{de}$ \\
$\mathrm{S}_{8}\left(\mathrm{I}_{2} \mathrm{Kp}_{4}\right)$ & 1.39 & 2.34 & 3.65 & 4.49 & 5.41 & 6.52 & $3.96 \mathrm{~b}$ \\
$\mathrm{~S}_{9}$ & $1.37 \mathrm{f}$ & $2.29 \mathrm{e}$ & $3.43 \mathrm{~d}$ & $4.09 \mathrm{c}$ & $5.00 \mathrm{~b}$ & $6.08 \mathrm{a}$ &
\end{tabular}

${ }^{\mathrm{z}}$ Aynı harfle gösterilmeyen ortalamalar arasındaki fark önemlidir $(\mathrm{p}<0.05)$.

Muhafaza süresi ve uygulamaların meyve eti sertliği değerleri üzerine etkisi Tablo 3'de verilmiştir. Başlangıçta ortalama $16.93 \mathrm{lb}$ olan meyve eti sertliği, muhafaza süresince sürekli azalış göstermiş, depolamanın 6. ayı sonunda ortalama $11.73 \mathrm{lb}$ olarak belirlenmiştir. Uygulamaların meyve eti sertliği değerleri üzerindeki etkisi önemli bulunmuştur. $\mathrm{S}_{1}$ ve $\mathrm{S}_{5}$ uygulamaları sırasıyla ortalama $14.46 \mathrm{lb}$ 
ve $14.39 \mathrm{lb}$ değerleri ile meyve eti sertliğinin korunmasında en iyi uygulamalar olarak belirlenmiştir. Kısitlı sulama uygulamalarıyla daha sert meyvelerin elde edilmesi hücresel hidrasyondaki azalma ve meyve eti sıkılığındaki artışa bağlanabilir [11]. Kısıtlı sulama uygulamalarından depolama süresince elmalarda önemli derecede daha yüksek meyve eti sertliği değerleri elde edildiği bildirilmiştir [11,12]. En düşük meyve eti sertliği değerleri ise $S_{8}(13.02 \mathrm{lb}), S_{3}(13.32 \mathrm{lb})$ ve $S_{9}(13.22)$ uygulamalarının meyvelerinde saptanmıştır. Meyve eti sıkılığında meydana gelen yumuşama, olgunlaşma sırasında hücre duvarında meydana gelen değişikliklerden kaynaklanmaktadır [13].

Tablo 3. Starkrimson Delicious elma ceşidinde muhafaza süresince saptanan meyve eti sertlik değerleri (lb)

\begin{tabular}{|c|c|c|c|c|c|c|c|c|}
\hline \multirow[b]{2}{*}{ Uygulama } & \multicolumn{8}{|c|}{ Muhafaza Süresi (Ay) } \\
\hline & $\mathbf{0}$ & 1 & 2 & 3 & 4 & 5 & 6 & $\begin{array}{c}\text { Uygulama } \\
\text { Ortalamaları }\end{array}$ \\
\hline $\mathrm{S}_{1}\left(\mathrm{I}_{1} \mathrm{Kp}_{1}\right)$ & 17.21 & 15.39 & 15.97 & 13.82 & 13.28 & 13.09 & 12.48 & $14.46 \mathrm{a}^{\mathrm{z}}$ \\
\hline $\mathrm{S}_{2}\left(\mathrm{I}_{1} \mathrm{Kp}_{2}\right)$ & 17.12 & 15.53 & 14.49 & 13.74 & 12.93 & 12.74 & 12.39 & $14.13 \mathrm{~b}$ \\
\hline $\mathrm{S}_{3}\left(\mathrm{I}_{1} \mathrm{Kp}_{3}\right)$ & 16.51 & 14.47 & 14.56 & 12.86 & 11.94 & 11.23 & 11.66 & $13.32 \mathrm{e}$ \\
\hline $\mathrm{S}_{4}\left(\mathrm{I}_{1} \mathrm{Kp}_{4}\right)$ & 17.14 & 14.69 & 14.65 & 13.71 & 12.45 & 12.04 & 12.22 & $13.84 \mathrm{c}$ \\
\hline $\mathrm{S}_{5}\left(\mathrm{I}_{2} \mathrm{Kp}_{1}\right)$ & 17.70 & 15.40 & 15.41 & 13.95 & 13.07 & 13.03 & 12.20 & $14.39 \mathrm{a}$ \\
\hline $\mathrm{S}_{6}\left(\mathrm{I}_{2} \mathrm{Kp}_{2}\right)$ & 16.91 & 14.74 & 14.17 & 13.37 & 11.88 & 12.23 & 11.11 & $13.49 \mathrm{~d}$ \\
\hline $\mathrm{S}_{7}\left(\mathrm{I}_{2} \mathrm{Kp}_{3}\right)$ & 16.73 & 14.39 & 15.13 & 13.28 & 12.84 & 12.40 & 11.80 & $13.80 \mathrm{c}$ \\
\hline $\mathrm{S}_{8}\left(\mathrm{I}_{2} \mathrm{Kp}_{4}\right)$ & 16.43 & 13.55 & 14.38 & 12.95 & 11.64 & 11.44 & 10.75 & $13.02 \mathrm{f}$ \\
\hline $\mathrm{S}_{9}$ & 16.65 & 14.01 & 14.17 & 12.87 & 12.15 & 11.77 & 10.96 & $13.22 \mathrm{e}$ \\
\hline $\begin{array}{l}\text { Muhafaza } \\
\text { süresi ort. }\end{array}$ & $16.93 \mathrm{a}$ & $14.68 \mathrm{~b}$ & $14.77 \mathrm{~b}$ & $13.39 \mathrm{c}$ & $12.46 \mathrm{~d}$ & $12.22 \mathrm{e}$ & $11.73 \mathrm{f}$ & \\
\hline
\end{tabular}

Meyvelerin TEA miktarları üzerine depolama süresi ve uygulamaların etkisi istatistiksel olarak önemli $(\mathrm{p}<0.05)$ bulunmuştur. Depolama sonunda tüm uygulamalarda meyvelerin TEA miktarı, başlangıca göre bir azalma göstermiş̧tir (Tablo 4). Derim zamanında ortalama $0.35 \mathrm{~g} / 100 \mathrm{ml}$ olan TEA miktarı, muhafaza süresi sonunda ortalama $0.31 \mathrm{~g} / 100 \mathrm{ml}$ olarak belirlenmiştir. Benzer olarak kısıtlı sulama programları uygulamaları sonrasında yapılan elma muhafaza çalışmalarında da titre edilebilir asitliğin depolama süresince azalarak gittiği bildirilmiştir [11, 12, 14]. Depolama süresince titre edilebilir asit miktarındaki azalmanın malik asidin meyve solunumda metabolit substrat olarak tüketilmesinden kaynaklanmaktadır [15]. Muhafaza periyodu süresince titre edilebilir asit miktarındaki en az azalmayı veren A sınıfı buharlaşma kabından olan buharlaşma toplamının \%50'si kadar sulama suyu uygulamasını $(0.37 \mathrm{~g} / 100 \mathrm{ml})$ ortalama $0.35 \mathrm{~g} / 100 \mathrm{ml}$ ile A sınıfı buharlaşma kabından olan buharlaşma toplamının \%75'i kadar sulama suyu uygulaması takip etmiş̧ir. TEA miktarında meydana gelen en fazla kayıp A sınıfı buharlaşma kabından olan buharlaşma toplamının \%100'ü kadar sulama suyu ve 20 gün sulama aralığında her sulamada 0-120 cm toprak derinliğindeki mevcut nemi tarla kapasitesine getirecek kadar sulama suyu uygulamalarında $(0.31 \mathrm{~g} / 100 \mathrm{ml})$ gözlenmiştir. Elmalarda yapılan sulama çalışmalarında kısıtlı sulama uygulamalarının depolama sonunda optimum ve fazla sulama uygulamalarına göre meyvelerdeki asit miktarının daha fazla olduğu bildirilmiştir [16,17]. 
Onursal CE., Küçükyumuk C., Çalhan Ö., Eren İ.

Tablo 4. Starkrimson Delicious elma çeşidinde muhafaza süresince saptanan TEA miktarı (g/100 ml)

\begin{tabular}{|c|c|c|c|c|c|c|c|c|}
\hline \multirow[b]{2}{*}{ Uygulama } & \multicolumn{8}{|c|}{ Muhafaza Süresi (Ay) } \\
\hline & $\mathbf{0}$ & 1 & 2 & 3 & 4 & 5 & 6 & $\begin{array}{l}\text { Uygulama } \\
\text { Ort. }\end{array}$ \\
\hline $\mathrm{S}_{1}\left(\mathrm{I}_{1} \mathrm{Kp}_{1}\right)$ & 0.36 & 0.36 & 0.38 & 0.37 & 0.37 & 0.38 & 0.37 & $0.37 \mathrm{a}^{\mathrm{z}}$ \\
\hline $\mathrm{S}_{2}\left(\mathrm{I}_{1} \mathrm{Kp}_{2}\right)$ & 0.35 & 0.35 & 0.34 & 0.36 & 0.37 & 0.37 & 0.31 & $0.35 \mathrm{~b}$ \\
\hline $\mathrm{S}_{3}\left(\mathrm{I}_{1} \mathrm{Kp}_{3}\right)$ & 0.35 & 0.34 & 0.34 & 0.32 & 0.29 & 0.28 & 0.29 & $0.31 \mathrm{e}$ \\
\hline $\mathrm{S}_{4}\left(\mathrm{I}_{1} \mathrm{Kp}_{4}\right)$ & 0.35 & 0.37 & 0.33 & 0.34 & 0.30 & 0.28 & 0.32 & $0.33 \mathrm{~d}$ \\
\hline $\mathrm{S}_{5}\left(\mathrm{I}_{2} \mathrm{Kp}_{1}\right)$ & 0.34 & 0.32 & 0.35 & 0.35 & 0.34 & 0.30 & 0.30 & $0.33 \mathrm{~d}$ \\
\hline $\mathrm{S}_{6}\left(\mathrm{I}_{2} \mathrm{Kp}_{2}\right)$ & 0.37 & 0.35 & 0.34 & 0.34 & 0.31 & 0.32 & 0.30 & $0.33 \mathrm{~cd}$ \\
\hline $\mathrm{S}_{7}\left(\mathrm{I}_{2} \mathrm{Kp}_{3}\right)$ & 0.34 & 0.33 & 0.33 & 0.32 & 0.34 & 0.32 & 0.29 & 0.32 de \\
\hline $\mathrm{S}_{8}\left(\mathrm{I}_{2} \mathrm{Kp}_{4}\right)$ & 0.35 & 0.35 & 0.35 & 0.35 & 0.32 & 0.32 & 0.35 & 0.34 bc \\
\hline $\mathrm{S}_{9}$ & 0.35 & 0.31 & 0.31 & 0.33 & 0.32 & 0.28 & 0.28 & $0.31 \mathrm{e}$ \\
\hline $\begin{array}{l}\text { Muhafaza } \\
\text { süresi ort. }\end{array}$ & $0.35 \mathrm{a}$ & $0.34 \mathrm{a}$ & $0.34 \mathrm{a}$ & $0.34 \mathrm{a}$ & $0.33 \mathrm{~b}$ & $0.32 \mathrm{c}$ & $0.31 \mathrm{c}$ & \\
\hline
\end{tabular}

${ }^{\mathrm{z}}$ Aynı harfle gösterilmeyen ortalamalar arasındaki fark önemlidir $(\mathrm{p}<0.05)$.

Starkrimson Delicious elma çeşidinde muhafaza süresi ve uygulamalara göre belirlenen SÇKM miktarları Tablo 5'de verilmiştir. Muhafaza süresinin başında \%13.43 olan SÇKM miktarı, muhafaza süresince önce artarak 4. ayda \%15.64 değerine ulaşmıştır. Daha sonraki dönemlerde azalarak depolama sonunda \%15.07 değerine kadar düşmüştür. Muhafaza süresi ve uygulamaların SÇKM üzerine etkileri istatistiksel olarak önemli $(\mathrm{p}<0.05)$ bulunmuştur. Uygulamaların SÇKM miktarı üzerine etkisi incelendiğinde muhafaza süresince SÇKM miktarındaki en az azalma sırasıyla 4 ve 7 gün sulama aralıklarında A sınıfı buharlaşma kabından olan buharlaşma toplamının \%50'si (\%16.04, \%15.82) ve 4 gün sulama aralığında \%75'i kadar (\%15.70) sulama suyu uygulamalarındaki elmalarda belirlenmiştir. Kısıtlı sulamanın elma depolaması sırasında SÇKM üzerine benzer etkileri daha önce yapılan çalışmalarda bildirilmiştir $[10,18]$.

Tablo 5. Starkrimson Delicious elma çeşidinde muhafaza süresince saptanan SÇKM değerleri (\%)

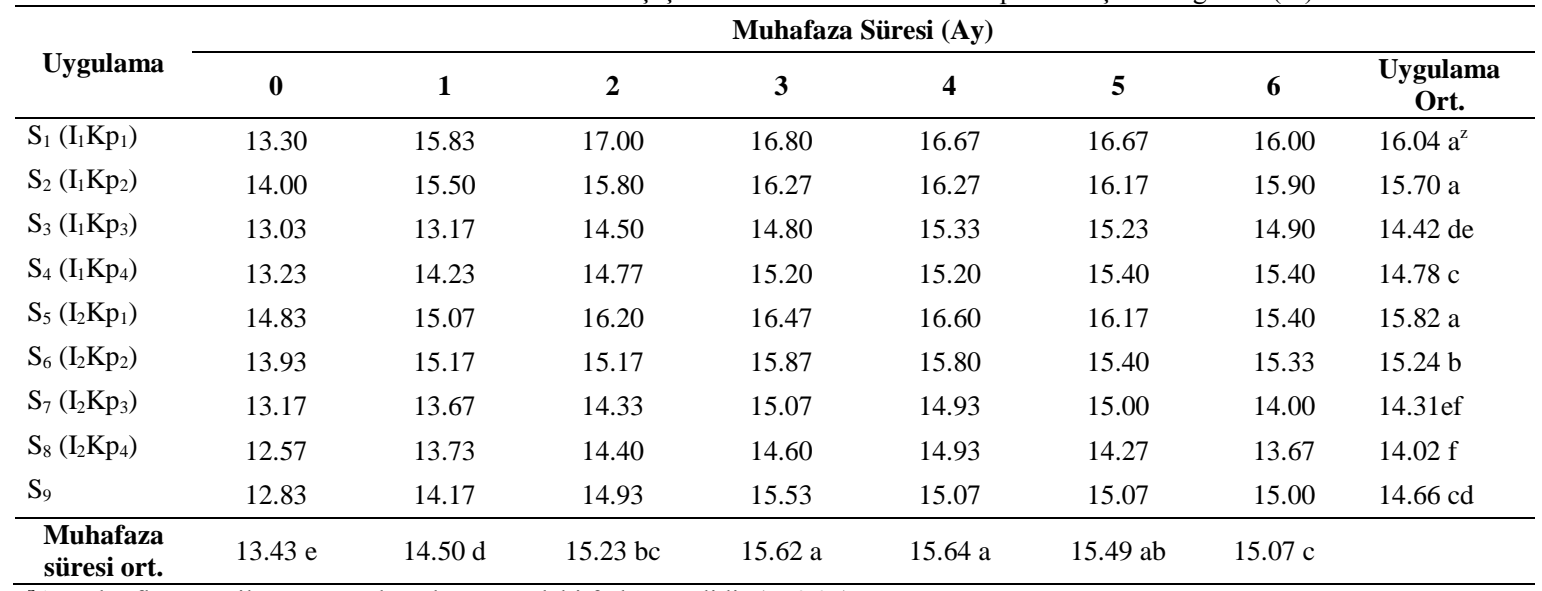

${ }^{\mathrm{z}}$ Aynı harfle gösterilmeyen ortalamalar arasındaki fark önemlidir $(\mathrm{p}<0.05)$.

Muhafaza süresince meyve kabuk rengi değişimi incelendiğinde (Tablo 6, 7, 8) depolama süresi ve uygulamaların kabuk rengi değişimi üzerine etkisi istatistiksel olarak önemli bulunmuştur. Depolama sonunda bütün uygulamalara ait meyvelerin renginde başlangıca göre $\mathrm{L}^{*}$ değerinde azalma yani koyulaşma olduğu ve açıklık değeri üzerine uygulamaların farklı etki yaptığı belirlenmiştir. L* değerinde depolama sonunda en az değişim sırasıyla 7 gün sulama aralığında $\mathrm{A}$ sınıfı buharlaşma kabından olan buharlaşma toplamının $\% 50$ 'si, $\% 125$ 'i, $\% 75$ 'i kadar sulama suyu ve 4 gün sulama aralığında A sınıfi buharlaşma kabından olan buharlaşma toplamının \%50'si kadar sulama suyu uygulamalarından elde 
edilmiştir. $a^{*}$ ve $b^{*}$ değerlerindeki değişim incelendiğinde depolama sonunda $a^{*}$ değerindeki en az değişim 4 gün sulama aralığında A sınıfı buharlaşma kabından olan buharlaşma toplamının \%100'ü kadar sulama suyu uygulamasından elde edilirken $b^{*}$ değerindeki en az değişim 7 gün sulama aralığındaki A sınıfı buharlaşma kabından olan buharlaşma toplamının \%50'si kadar sulama suyu uygulamasından elde edilmiştir.

Tablo 6. Starkrimson Delicious elma çeșidinde muhafaza süresince meyve kabuğunun $L *$ değerinde meydana gelen değișim

\begin{tabular}{lcccccccc}
\hline \multirow{2}{*}{ Uygulama } & \multicolumn{7}{c}{ Muhafaza Süresi (Ay) } \\
\cline { 2 - 9 } & $\mathbf{0}$ & $\mathbf{1}$ & $\mathbf{2}$ & $\mathbf{3}$ & $\mathbf{4}$ & $\mathbf{5}$ & $\mathbf{6}$ & $\begin{array}{c}\text { Uygulama } \\
\text { Ort. }\end{array}$ \\
\hline $\mathrm{S}_{1}\left(\mathrm{I}_{1} \mathrm{Kp}_{1}\right)$ & 43.39 & 42.68 & 42.29 & 42.82 & 42.28 & 42.64 & 41.74 & $42.55 \mathrm{a}^{\mathrm{z}}$ \\
$\mathrm{S}_{2}\left(\mathrm{I}_{1} \mathrm{Kp}_{2}\right)$ & 40.79 & 39.94 & 39.67 & 39.27 & 39.78 & 39.54 & 39.15 & $39.73 \mathrm{bc}$ \\
$\mathrm{S}_{3}\left(\mathrm{I}_{1} \mathrm{Kp}_{3}\right)$ & 40.90 & 40.49 & 40.11 & 39.79 & 39.61 & 39.76 & 39.42 & $40.01 \mathrm{bc}$ \\
$\mathrm{S}_{4}\left(\mathrm{I}_{1} \mathrm{Kp}_{4}\right)$ & 41.33 & 40.74 & 40.11 & 40.77 & 39.97 & 39.85 & 39.67 & $40.35 \mathrm{~b}$ \\
$\mathrm{~S}_{5}\left(\mathrm{I}_{2} \mathrm{Kp}_{1}\right)$ & 44.42 & 43.57 & 43.66 & 43.05 & 43.46 & 42.97 & 42.74 & $43.41 \mathrm{a}$ \\
$\mathrm{S}_{6}\left(\mathrm{I}_{2} \mathrm{Kp}_{2}\right)$ & 43.75 & 43.48 & 42.70 & 42.99 & 42.63 & 41.86 & 42.31 & $42.82 \mathrm{a}$ \\
$\mathrm{S}_{7}\left(\mathrm{I}_{2} \mathrm{Kp}_{3}\right)$ & 41.32 & 40.33 & 39.95 & 40.02 & 40.19 & 39.45 & 39.96 & $40.17 \mathrm{~b}$ \\
$\mathrm{~S}_{8}\left(\mathrm{I}_{2} \mathrm{Kp}_{4}\right)$ & 43.58 & 43.76 & 42.69 & 42.33 & 42.74 & 42.58 & 42.37 & $42.86 \mathrm{a}$ \\
$\mathrm{S}_{9}$ & 41.01 & 39.79 & 38.98 & 39.10 & 39.14 & 37.48 & 38.35 & $39.12 \mathrm{c}$ \\
\hline Muhafaza & $42.28 \mathrm{a}$ & $41.64 \mathrm{ab}$ & $41.13 \mathrm{bc}$ & $41.13 \mathrm{bc}$ & $41.09 \mathrm{bc}$ & $40.68 \mathrm{c}$ & $40.63 \mathrm{c}$ & \\
süresi ort. & &
\end{tabular}

${ }^{\mathrm{z}}$ Aynı harfle gösterilmeyen ortalamalar arasındaki fark önemlidir $(\mathrm{p}<0.05)$.

Tablo 7. Starkrimson Delicious elma çeşidinde muhafaza süresince meyve kabuğunun a*değerinde meydana gelen değişim

\begin{tabular}{lcccccccc}
\hline \multirow{2}{*}{ Uygulama } & \multicolumn{7}{c}{ Muhafaza Süresi (Ay) } \\
\cline { 2 - 9 } & $\mathbf{0}$ & $\mathbf{1}$ & $\mathbf{2}$ & $\mathbf{3}$ & $\mathbf{4}$ & $\mathbf{5}$ & $\mathbf{6}$ & $\begin{array}{c}\text { Uygulama } \\
\text { Ort. }\end{array}$ \\
\hline $\mathrm{S}_{1}\left(\mathrm{I}_{1} \mathrm{Kp}_{1}\right)$ & 24.39 & 26.89 & 26.45 & 24.74 & 23.12 & 22.63 & 20.49 & $24.10 \mathrm{~d}^{\mathrm{z}}$ \\
$\mathrm{S}_{2}\left(\mathrm{I}_{1} \mathrm{Kp}_{2}\right)$ & 27.12 & 29.65 & 29.16 & 28.58 & 27.43 & 26.03 & 24.00 & $27.42 \mathrm{bc}$ \\
$\mathrm{S}_{3}\left(\mathrm{I}_{1} \mathrm{Kp}_{3}\right)$ & 29.21 & 32.07 & 32.61 & 30.24 & 27.93 & 25.90 & 23.64 & $28.80 \mathrm{a}$ \\
$\mathrm{S}_{4}\left(\mathrm{I}_{1} \mathrm{Kp}_{4}\right)$ & 26.01 & 29.15 & 29.31 & 27.62 & 25.98 & 25.41 & 23.04 & $26.65 \mathrm{c}$ \\
$\mathrm{S}_{5}\left(\mathrm{I}_{2} \mathrm{Kp}_{1}\right)$ & 24.72 & 26.80 & 26.10 & 25.20 & 23.85 & 21.99 & 19.92 & $24.08 \mathrm{~d}$ \\
$\mathrm{~S}_{6}\left(\mathrm{I}_{2} \mathrm{Kp}_{2}\right)$ & 24.35 & 27.77 & 27.28 & 24.43 & 22.41 & 21.66 & 19.57 & $23.93 \mathrm{~d}$ \\
$\mathrm{~S}_{7}\left(\mathrm{I}_{2} \mathrm{Kp}_{3}\right)$ & 27.18 & 29.64 & 29.94 & 27.17 & 26.59 & 25.44 & 22.60 & $26.94 \mathrm{c}$ \\
$\mathrm{S}_{8}\left(\mathrm{I}_{2} \mathrm{Kp}_{4}\right)$ & 23.25 & 26.70 & 26.53 & 24.43 & 23.21 & 21.27 & 19.24 & $23.52 \mathrm{~d}$ \\
$\mathrm{~S}_{9}$ & 28.06 & 30.88 & 31.06 & 30.05 & 27.62 & 26.53 & 23.38 & $28.23 \mathrm{ab}$ \\
\hline \multicolumn{1}{c}{ Muhafaza } \\
süresi ort. & $26.03 \mathrm{c}$ & $28.84 \mathrm{a}$ & $28.72 \mathrm{a}$ & $26.94 \mathrm{~b}$ & $25.35 \mathrm{c}$ & $24.10 \mathrm{~d}$ & $21.76 \mathrm{e}$ & \\
\hline
\end{tabular}

${ }^{ }$Aynı harfle gösterilmeyen ortalamalar arasındaki fark önemlidir $(\mathrm{p}<0.05)$.

Tablo 8. Starkrimson Delicious elma çeşidinde muhafaza süresince meyve kabuğunun $b *$ değerinde meydana gelen değişim

\begin{tabular}{lcccccccc}
\hline \multirow{2}{*}{ Uygulama } & \multicolumn{7}{c}{ Muhafaza Süresi (Ay) } \\
\cline { 2 - 9 } & $\mathbf{0}$ & $\mathbf{1}$ & $\mathbf{2}$ & $\mathbf{3}$ & $\mathbf{4}$ & $\mathbf{5}$ & $\mathbf{6}$ & $\begin{array}{c}\text { Uygulama } \\
\text { Ort. }\end{array}$ \\
\hline $\mathrm{S}_{1}\left(\mathrm{I}_{1} \mathrm{Kp}_{1}\right)$ & 21.78 & 22.82 & 23.16 & 23.52 & 24.97 & 24.57 & 24.42 & $23.61 \mathrm{ab}^{\mathrm{z}}$ \\
$\mathrm{S}_{2}\left(\mathrm{I}_{1} \mathrm{Kp}_{2}\right)$ & 19.66 & 21.61 & 21.86 & 21.55 & 22.07 & 22.53 & 22.28 & $21.65 \mathrm{e}$ \\
$\mathrm{S}_{3}\left(\mathrm{I}_{1} \mathrm{Kp}_{3}\right)$ & 21.40 & 22.42 & 23.08 & 22.30 & 22.96 & 23.82 & 22.69 & $22.67 \mathrm{c}$ \\
$\mathrm{S}_{4}\left(\mathrm{I}_{1} \mathrm{Kp}_{4}\right)$ & 19.87 & 21.64 & 21.87 & 21.77 & 22.64 & 22.71 & 22.64 & $21.88 \mathrm{de}$ \\
$\mathrm{S}_{5}\left(\mathrm{I}_{2} \mathrm{Kp}_{1}\right)$ & 22.51 & 23.64 & 23.98 & 23.87 & 24.85 & 25.97 & 24.54 & $24.20 \mathrm{a}$ \\
$\mathrm{S}_{6}\left(\mathrm{I}_{2} \mathrm{Kp}_{2}\right)$ & 22.10 & 23.11 & 23.19 & 23.12 & 24.30 & 25.67 & 25.14 & $23.81 \mathrm{ab}$ \\
$\mathrm{S}_{7}\left(\mathrm{I}_{2} \mathrm{Kp}_{3}\right)$ & 21.27 & 22.55 & 22.76 & 22.62 & 22.62 & 24.10 & 22.17 & $22.58 \mathrm{~cd}$ \\
$\mathrm{~S}_{8}\left(\mathrm{I}_{2} \mathrm{Kp}_{4}\right)$ & 21.63 & 22.89 & 22.91 & 23.20 & 23.61 & 25.19 & 23.18 & $23.23 \mathrm{bc}$ \\
$\mathrm{S}_{9}$ & 19.23 & 20.23 & 20.37 & 20.29 & 20.23 & 22.00 & 20.57 & $20.42 \mathrm{f}$ \\
\hline \multicolumn{2}{c}{ Muhafaza } \\
süresi ort. & $21.05 \mathrm{~d}$ & $22.32 \mathrm{c}$ & 22.58 bc & $22.47 \mathrm{bc}$ & $23.14 \mathrm{~b}$ & $24.06 \mathrm{a}$ & $23.07 \mathrm{~b}$ & \\
\hline${ }^{\mathrm{z}}$ Ayn harfle gösterilmeyen ortalamalar arasindaki fark önemlidir $(\mathrm{p}<0.05)$. & & & &
\end{tabular}




\section{Sonuç}

Verim çağında uzun yıllardır yüzey sulama (salma) yöntemleri ile sulanan elma ağaçlarında, damla sulama yöntemi kullanılmaya başlanılmasının depolama süresince meyve kalitesine olumlu etkileri olduğu belirlenmiştir. Böylece üreticiler tarafından belirtilen sulama sisteminin değişmesiyle beraber meyve kalitesinin azalacağı yönündeki kaygıların yersiz olduğu ortaya konmuştur. Kısıtlı sulama uygulamalarının aşırı sulama $\left(\mathrm{Kp}_{4}\right)$ uygulamasına göre meyve kalitesinin korunmasında daha etkili olduğu belirlenmiştir. İncelenen tüm kriterler beraber değerlendirildiğinde 4 gün sulama aralığında $\mathrm{Kp}_{2}$ uygulaması muhafaza süresince kalite kriterlerini en iyi koruyan uygulama olmuştur.

\section{Kaynaklar}

[1] TUIK, http://www.tuik.gov.tr/UstMenu.do?metod=temelist. Erişim Tarihi: 23.02.2015

[2] Anonim, “TC. Gıda Tarım ve Hayvancılık Bakanlığı, Strateji Geliştirme Başkanlığı, Tarımsal Yatırımcı Danışma Ofisi, Isparta İli Tarımsal Yatırım Rehberi”, 2015.

[3] Yazgan, S., Büyükcangaz, H., Demirtaş, Ç., Candoğan, B.N., “Genç kiraz ağaçlarında (Prunus avium) farklı sulama programlarının vejetatif gelişme parametreleri ve bitki su tüketimi üzerine etkileri” Uludag.Üniv.Zir.Fak.Dergisi, 18(2): 1-12, 2004

[4] Karaçalı, İ., “Bahçe Ürünlerinin Muhafaza ve Pazarlanması” Ege Üniv.Zir.Fak.Yayınları No:494 Bornova/İzmir, s. 149, 2009

[5] Karamürsel, K., Öztürk, F.P., Öztürk, G., Kaymak, S., Eren, İ., Akgül, H., "Eğirdir yöresi elma yetiştiriciliğinin durumu ve sorunlarının belirlenmesi ile ekonomik yönden değerlendirilmesi” Tarımsal Araştırmalar Genel Müdürlüğü Eğirdir Bahçe Kültürleri Araştırma Enstitüsü, 72 s., 2003

[6] Yıldırım, M., Yıldırım, O., "Damla sulamada farklı sulama programlarının erik ağaçlarında meyve verimi ve ağaç gelişimi üzerine etkileri” Uludag.Üniv.Zir.Fak.Dergisi, 19(1): 37-49, 2005

[7] Gültaş, H., Erdem, Y., "Bodur kiraz bahçelerinde damla ve mikro yağmurlama sulama yöntemlerinin yatırım ve işletme masrafları yönünden karşılaştırılması” Tarım Bilimleri Dergisi, 13 (1) 38-46., 2006

[8] Küçükyumuk, C., Ay., Z., "Meyve Yetiştiriciliğinde Yüzey Sulama Yönteminden Damla Sulama Yöntemine Geçişte Yapılan Hatalar ve Çözüm Yolları” 1. Ulusal Toprak ve Su Kaynakları Kongresi, 1-4 Haziran 2010, (sözlü bildiri), 232-238, Eskişehir, 2010

[9] Eren, İ., "M9 anacı üzerine aşı1ı bazı elma çeşitlerinin derim zamanlarının belirlenmesi ve uygun depolama koşullarının araştırılması" Yüksek Lisans Tezi, Süleyman Demirel Üniversitesi, Isparta, 2003

[10] Crisosto,C.H., Jonson,R.S., Luza, J.G., Crisosto, G.M., “ Irrigation regimes affect fruit soluble solids concentrations and rate of water loss of 'O'Henry peaches” Hortscience 29(10):11691171,1994

[11] Mpelasoka, B.S., Behboudian, M.H., Dixon, J., Neal, S.M., Caspari, H.W., “ Improvement of fruit quality and storage potential of 'Braeburn' apple trough deficit irrigation” J. Hortic. Sci. Biotech. 75:615-621, 2000 
[12] Wan Zaliha, W.S, Singh, Z., " Impact of regulated deficit irrigation on fruit quality and postharvest storage performance of ‘Cripps Pink’ apple” Acta Hort. 877:155-162, 2010a

[13] Hobson, G.E, “ Enzymes and texture changes during ripening. In: J. Friend and M.J.C. Rhodes. Recent Advances in the Biochemistry of Fruitsand Vegetables” Academic Pres, London. p.121132, 1981

[14] Ebel, R. C., Proebstıng E. L., Patterson M. E., “ Regulated deficit irrigation may alter apple maturity, quality, and storage life” Hortscience. vol. 28, no 2, pp. 85-95 (20 ref.), pp. 141-143, 1993

[15] Ackerman, J., Fisher, M., Amado, R.. Changes in sugars, acids, amino acids during ripening and storage of apples (cv. Glockenapfel). J.Agric.Food Chem. 40:1131-1134, 1992

[16] Mills, T.M., Behboudian, M.H., Clothier, B.E., “ Preharvest and storage quality of "breaburn” apple fruit grown under water deficit conditions" New Zealand Journal of Crop and Horticultural Science. 24:2, 159-166, 1996

[17] Wan Zaliha, W.S, Singh, Z., “ Fruit quality and postharvest performance of 'Cripps Pink' apple in relation to witholding irrigation” Acta Hort. 877:147-154, 2010b

[18] Kilili, A.V., Behbohudian, M.H., Mills, T.M., “ Postharvest performance of 'breaburn' apples in relation to witholding of irrigation at different stages of growing season” J.Hortic.Sci. 71:693701, 1996 